\title{
The Integration and Upgrade of the New Media Era and the Film Industry
}

\author{
Wen Feng ${ }^{1, *}$ \\ ${ }^{1}$ Communication University of China, Beijing, China \\ *Corresponding author. Email: fengwenfw@qq.com
}

\begin{abstract}
The background of new media is technological change and innovation. This is an era of development. When new media meets movies, a wonderful chemical reaction occurs. The new media film industry is both an opportunity and a challenge for the traditional film industry. New media movies also rely on their own unique advantages to occupy a place in the film and television industry. This article will tentatively analyze the new media and film industry to explore their own characteristics and the new pattern of their integration.
\end{abstract}

Keywords: New media, Film industry, Development, Integration.

\section{INTRODUCTION}

As everything is changing, what come with the changes are the products of a new era that changes with each passing day. The rapid progress of material civilization is accompanied by the urgent demands of spiritual civilization. In this new era, the media industry has also undergone earthshaking changes on the new stage. From traditional media to the mobile Internet, people's lives have been inseparable from the media. The Internet era has changed people's inherent lifestyles, whether it is work, life, study, or entertainment. It has made people look at the world again at a rapid pace. According to the viewpoint of media ecosystem theory, human, media, society, and nature form a dynamic and balanced unity of mutual influence, interdependence and interaction. [1]

New media is a new means of information dissemination and communication compared with traditional media. [2] It has the advantages of interactivity, immediacy, massive information, integration, and mass decentralization. The dissemination of personalized content has changed the original way of dissemination. The sender and receiver of the information form a peer-to-peer exchange, and at the same time, the audience can communicate with each other freely. The new media industry is a path of continuous progress. The evolution process is inseparable from the development of science and technology. As an important part of the cultural and creative industry, it is also an important branch of the tertiary industry and an inseparable organic component of the development of the national economy. Since the development of film and television art, people have discovered its commercial value. In 1895, when people saw the scene of "Train entering in the station", they were almost frightened by the images in front of them. This unique art form stimulates the sensory nerves of the audience with strong and shocking audio-visual effects. From art to commerce, the most intuitive test of movies is the audience. Following in the footsteps of the times, the film industry has gradually shifted from singularity to diversification. When the new media and the film industry met, a wonderful chemical reaction occurred between the two.

\section{THE IMPACT OF THE NEW MEDIA INDUSTRY ON THE FILM INDUSTRY}

With the advent of the new media era and the rapid development of mobile terminals, online video and mobile phone video are playing an increasingly important role in people's life and entertainment. Mobile video takes advantage of people's fragmented time characteristics and provides the entertainment needs of a convenient life. This brand-new video broadcast method and increasingly mature broadcast platforms have had a 
huge impact and influence on the development of China's traditional film industry.

In the current state of technological development, online platforms are the main position of new media. Under the influence of this trend, as far as the film industry is concerned, it has also moved from a single theater model to the Internet. Every year in China, a large number of film and television works are produced, but a very small part of them can really enter the theaters and meet with the audience. Cinemas have high requirements for the production level of movies, and it is also one of the most powerful means of market testing. With people's craze for the Internet and the impact of new media, the film industry has undergone quiet changes. The movie producer cooperates with new media to promote and build momentum, and at the same time, the movie can be watched through the Internet. From theaters to the Internet, the audience has different choices.

Movies move from film to digital, marking the end of an era and the beginning of another era. The development and innovation of any kind of technology will inevitably bring about changes in the industry. The emergence of new media films has promoted the new development direction of China's traditional film industry and expanded the development space of the traditional film industry. [3] Objectively speaking, the development of the new media industry is an opportunity and a challenge for traditional Chinese movies. New media movies have lowered the barriers to film broadcasting, enabling movies that have not been able to enter the theater line to the public through the Internet. At the same time, the film industry has also changed its original marketing methods due to the influence of new media. Compared with traditional media, new media can spread information more widely. The relevant data is statistically available, which provides marketers with more accurate information to adjust their marketing strategies. In the consumer sector, new media has added a variety of options for movie box office sales, reduced time costs, and improved its own efficiency. Today, a close network of relationships has been formed between the two, interacting and promoting each other. The era of new media has not only brought about the evolution of various forms of film, but also has begun to appear in the film and new media technology and cultural integration, form integration, communication integration, and media integration. It can be seen that the digitization of movies and their all-round integration with new media will be the new development direction of national movies in the new media era. [4]

\section{EXPLORING THE ROAD OF NEW MEDIA FILM}

The film itself is a complementary combination of technology and artistry. The combination of new media and movies has brought a new spark. New media movies can be widely understood as video content that mainly relies on the Internet or digital media to spread. As a new product form, it is obviously different from traditional cinema movies. New media movies have their own unique characteristics in terms of early production costs, creative models, broadcasting channels, business models, as well as the people who work in the industry, the audience who watch them, and the interests of the industry chain. In this mode, the concept of "micro movies" was derived. The emergence of micro-movies is realized in the rapid progress of new media under the development of Internet media. It is similar to the basic film production process, but simplifies the corresponding implementation methods. The "micro" characteristics of micro movies are mainly reflected in four aspects: micro duration, micro cycle, micro scale, and micro platform. [5]

Film and television works are shot with superb and short production content. It is this feature that simplifies the production of micro-films, diversifies the way of dissemination, and achieves a high degree of compatibility with the new media environment. The rise of micro-films caused Chinese Internet video sites to establish their own micro-film channels and launch original micro-film projects. Among them, Youku Original, set off a wave of micro-film frenzy with the "11th Degree of Youth" movie action. It is worth mentioning that "Old Boy" directed by Xiao Yang, a member of the Chopsticks Brothers, triggered a heated discussion about new media movies. In just one week, the film has a hit rate of up to 50 million times. Topics, music, and stories about old boys all became popular online keywords. In addition to the artistry, the story content of the film is very contagious, and the shooting method is more meticulous. What's more important is to make the elegant art of the film popular, and the low-threshold micro-film allows everyone to participate. "Everyone is the director of life", this slogan has become the most intuitive feeling that new media movies convey to the public. At the same time of technological change, it has also changed the public's aesthetic 
conception and changed the aesthetics of daily life. The attitude of civilians has expanded the scope of communication as never before.

This kind of innovation in new media films has made many film practitioners see new opportunities. At the 15th Shanghai International Film Festival, the Golden Goblet Award for Best Director was won by Gao Qunshu, director of "Detective Hunter Zhang". The award speech of the jury is: the film subject is novel and unique, and the tone is dark but can't conceal the power of light. The director's choice of non-professional actors reflects the power of the film's simplicity. This kind of innovation is that the director used more than 30 Weibo celebrities as the starring roles for the first time, and a major background of the film's birth was the birth of the Weibo platform. "Detective Hunter Zhang" has also become an excellent model for the marriage between the movie world and the new media world.

\section{THE DIRECTION OF NEW MEDIA MOVIES WHEN FACING INDUSTRIAL UPGRADING}

New media movies conform to the development trend of the Internet age, and the development of traditional Chinese movies is bound to be affected by this pattern. However, compared with the traditional film industry, new media movies are still not comparable. In terms of communication, new media has created a new situation for the film industry, fully expressing publicity and marketing, brand promotion, and public opinion topics. The traditional film industry, centered on industrialization, has a more rigorous attitude and thinking. In new media movies, the grand narrative presented on the traditional screen is abandoned, and instead focuses on the fate of individuals and strives to tap the civilian perspective of individual thoughts. [6] Movies have a close relationship with technology. The upgrading of the industry will surely bring new horizons. However, while looking back at the progress, it is necessary to think more about how the new media film and traditional film industry should use the best and eliminate the dross in the face of future development. The power of the film is not only the enjoyment of the senses, but also the cultural connotation and spiritual power of its precipitation. Art creation must emphasize the value and depth of the work. The era of universal entertainment has provided diverse entertainment content to the lives of the people, but its impetuousness cannot be avoided. The value of new media movies should bring non-panentertainment spiritual content to the public in today's rapid material development. Under the short, flat and fast way of dissemination, the content of more connotative value and cultural inheritance need to be absorbed.

\section{CONCLUSION}

Behind the rapid development of the Internet of science and technology has triggered the rise and fall of various industries. As an important spiritual and material wealth of the human world, culture and art explain the story of an era. As far as the Chinese film industry is concerned, it is even more important to grasp the opportunities of new media films and deepen the artistic production methods in the new era to realize the integration and upgrading of China's traditional film industry and technology industry.

\section{AUTHORS' CONTRIBUTIONS}

This article is independently completed by Wen Feng.

\section{REFERENCES}

[1] Shao Peiren, On the Structure, Planning and Management of Media Ecosystem [J]. Journal of Zhejiang Normal University (Social Sciences), 2008 (2). (in Chinese)

[2] Zheng Wei, A Probe into the Effect of the Socialist Core Values in Shaping the Soul of the New Media Culture [J]. Journal of Jining Normal University, 2015, (4): 42-45. (in Chinese)

[3] Chen Chen, The Promotion and Influence of the New Media Film Industry on the Development of China's Film Industry [J]. Movie Review, 2012, (7): 76-77. (in Chinese)

[4] Chen Juan, An Analysis of the Development of China's Film Industry in the Era of New Media [J]. Movie Review, 2016, (08): 69-71. (in Chinese)

[5] Dege Jile, On the Artistic Characteristics and Development of Film and Television Editing in the Era of New Media [J]. Chinese Information, 2015, (8): 346-346. (in Chinese)

[6] Wei Di, A Brief Discussion on the Development and Influence of New Media Films [J]. Youth Writers (Chinese \& Foreign Arts), 2010, (5): 48-49, 88. (in Chinese) 